\section{Manual Strength}

\author{
B. Makofske ${ }^{1}$ and E. Power ${ }^{2}$ \\ ${ }^{1}$ Legal Psychology (Psychology and Law), \\ Neuropsychology, Clinical Psychology, Chicago \\ School of Professional Psychology, Chicago, IL, \\ USA \\ ${ }^{2}$ College of Saint Rose, Albany, NY, USA
}

\section{Synonyms}

Grip strength; Hand strength

\section{Definition}

Manual strength is the force exerted when gripping or grasping an object. Hand strength is measured using a hand dynamometer to determine strength and intensity of voluntary grip movements of the right and left hands. Understanding of manual strength can provide useful information regarding increases or declines in functioning, as well as everyday abilities such as dressing and feeding oneself. A measurement of grip strength can serve as a useful screening tool of one's overall health, as weakness is a sign of frailty. Hand strength can also be used as a general indicator of the cohesiveness of the central nervous system. Mild peripheral brain injuries may impair manual strength even after other symptoms, such as pain and numbness, have subsided. Increasing an individual's manual strength can be used to rehabilitate the impairment of functionality and at times is used during post-trauma rehabilitation. Exercising the hands can strengthen grip, increase dexterity, and improve mobility of the wrist. Exercise can also promote coordination, increase range of motion, help with balance training, and aid in overall recovery. Rehabilitation can strengthen the fingers, wrist, and forearm using both extension and flexion exercises.

\section{Cross-References}

Manual Dexterity

\section{References and Readings}

Bohannon, R. W. (2008). Hand-grip dynamometry predicts future outcomes in aging adults. Journal of Geriatric Physical Therapy, 31(1), 3-10.

Dean, R. S., \& Woodcock, R. W. (2003). Dean-woodcock neuropsychological battery. Itasca: Riverside.

Reitan, R. M. (1993). The Halsted-Reitan neuropsychological test battery. Tucson: Neuropsychology Press.

Roberts, H. C., Denison, H. J., Martin, H. J., Patel, H. P., Syddall, H., Cooper, C., \& Sayer, A. A. (2011). A review of the measurement of grip strength in clinical and epidemiological studies: Towards a standardised approach. Age and Ageing, 40(4), 423-429.

Strauss, E., Spreen, O., \& Sherman, E. (2006). A compendium of neurological tests: Administration, norms and commentary. New York: Oxford University Press. 